RMOTC TEST REPORT

DOE/RMOTC - 020138

\title{
CRYOGENIC TREATMENT OF PRODUCTION COMPONENTS IN HIGH-WEAR RATE WELLS
}

\author{
September 18, 2000 - September 24, 2001
}

Work performed under Rocky Mountain Oilfield Testing Center (RMOTC) CRADA 2000-010

Data of Publication: May 23, 2002

Author: Mark Milliken, RMOTC Project Coordinator

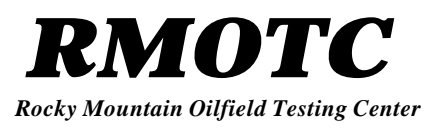

Approval:

RMOTC Manager Date 
This report was prepared as an account of work sponsored by an agency of the United States Government. Neither the United States Government nor any agency thereof, nor any of their employees, make any warranty, expresses or implied, nor assumes any legal liability or responsibility for the accuracy, completeness, or usefulness of any information, apparatus, product, or process disclosed, or represents that its use would not infringe privately owned rights. Reference herein to any specific commercial product, process, or service by trade name, trademark, manufacturer, or otherwise does not necessarily constitute or imply its endorsement, recommendation, or favoring by the United States Government or any agency thereof. The views and opinions of authors expressed herein do not necessarily state or reflect those of the United States Government or any agency thereof. 


\title{
CRYOGENIC TREATEMENT OF PRODUCTION COMPONENTS IN HIGH-WEAR RATE WELLS
}

\author{
CRADA 2000-010 \\ DOE Project Code 6730.02.0138 \\ Mark Milliken, Project Coordinator \\ October, 2001

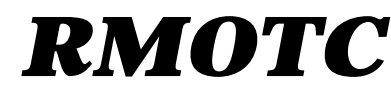 \\ Rocky Mountain Oilfield Testing Center
}

\begin{abstract}
Summary of results. Deep Cryogenic Tempering (DCT) is a specialized process whereby the molecular structure of a material is "re-trained" through cooling to $-300^{\circ} \mathrm{F}$ and then heating to $+175-1100^{\circ} \mathrm{F}$. Cryocon, Inc. (hereafter referred to as Cryocon) and RMOTC entered an agreement to test the process on oilfield production components, including rod pumps, rods, couplings, and tubing. Three Shannon Formation wells were selected (TD about $500 \mathrm{ft}$ ) based on their proclivity for high component wear rates.
\end{abstract}

Phase 1 of the test involved operation for a nominal 120 calendar day period with standard, non-treated components. In Phase 2, treated components were installed and operated for another nominal 120 calendar day period. Different cryogenic treatment profiles were used for components in each well. Rod pumps (two treated and one untreated) were not changed between test phases. One well was operated in pumped-off condition, resulting in abnormal wear and disqualification from the test. Testing shows that cryogenic treatment reduced wear of rods, couplers, and pump barrels. Testing of production tubing produced mixed results.

The problem. High wear rates in production components, including rods, couplings, pumps, pump valve rods, and tubing, can be caused by inclined well bores, hard tagging of rod pumps, improperly designed rod and tubing strings, high water-cut, and abrasive sediment loads. During normal operations, the effects include parted rod strings, poor pump performance, and perforated tubing, resulting in increased costly well maintenance and lost production.

Mitigation of the problem could save NPR3 tens of thousands of dollars per year in production, component, and labor costs. Within the ind ustry as a whole, the cost savings could be on the order millions of dollars per year. With these potential benefits in mind, RMOTC entered into a cost sharing partnership with Cryocon in anticipation that the investment would ultimately be recovered through reduced operating costs at NPR3.

Cryocon and their technology. Cryocon is a publicly traded company specializing in a proprietary material treatment process called Deep Cryogenic Tempering (DCT). DCT is 
a computer-controlled tempering process that, according to Cryocon, improves the wear and performance characteristics of many types of metals, alloys, and synthetic materials. DCT utilizes liquid nitrogen that is flashed to a gas to achieve temperatures of minus $300^{\circ} \mathrm{F}$. This technique is completely dry and eliminates the condition known as thermal shock, which is a problem related to traditional cryogenic applications involving spraying or dipping. Cryocon reports that some treated items show dramatic increases in wear resistance, toughness, machinability, and thermal and dimensional stability.

Deep Cryogenic Tempering is a specialized process whereby the molecular structure of a material is "re-trained" through cooling to $-300^{\circ} \mathrm{F}$ and then heating to $+175-1100^{\circ} \mathrm{F}$. Steel undergoes additional changes during Deep Cryogenic Tempering. One component of steel is austenite, a soft form of iron that lacks strength and durability. Traditional heat/quench tempering converts some of the austenite - but not all - into martensite, a harder form of iron. Deep Cryogenic Tempering converts nearly all the remaining austenite to martensite. The process can be used on most steel alloy that is heat-treatable, including cobalt, carbide, and carbon steels.

Cryogenic cooling pumps kinetic energy out of molecules. As temperatures approach minus $300^{\circ} \mathrm{F}$, a number of molecular changes take place:

- Super cooled molecules realign. Residual material stress is relieved during this molecular "settling."

- Super cooled molecules form stronger bonds, which yield improved material cohesion and resulting gains in performance and durability.

The heating phase is equally important because it:

- Further relieves residual stresses

- Reduces brittleness

During Deep Cryogenic Tempering, micro-fine carbide particles are formed, further strengthening the steel by filling micro-voids within the martensitic structure. According to Cryocon, the net result is a stronger, thermally stabilized material with a coherent, improved microstructure that exhibits outstanding wear resistance and improved performance. Not all cryogenic treatments are equally effective; improper super-cooling can damage or destroy an item. Cryocon has developed several optimal treatment profiles for numerous metals and alloys. Each treatment profile is controlled by computer to accuracy within $0.01^{\circ} \mathrm{F}$.

For the RMOTC test, Cryocon constructed a special modular cryogenic processor to contain the rods and tubing (Figures 1 and 2). The modular design allows easy adaptation to different sizes of oil field components. 


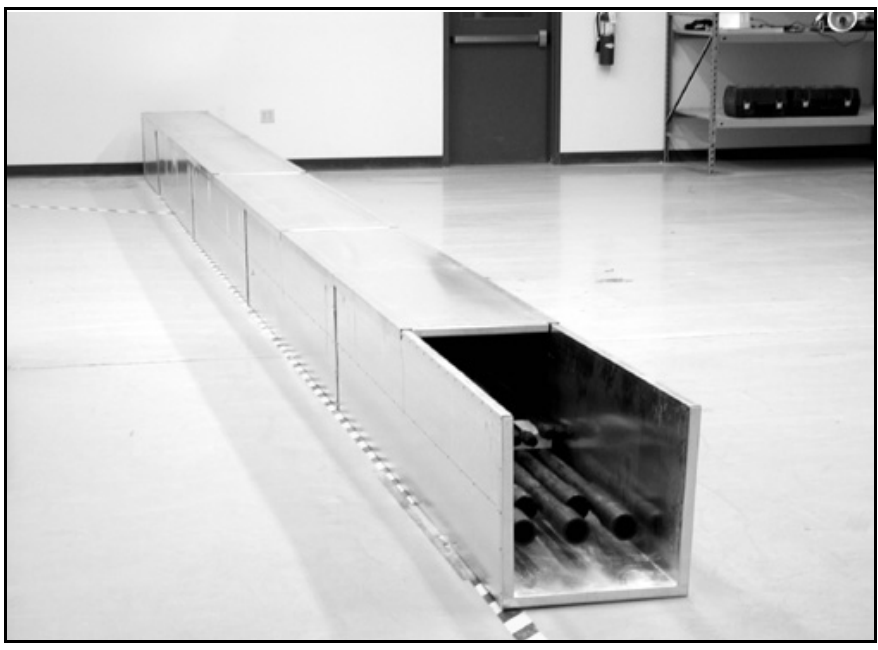

Figure 1. Cryocon's prototype cryogenic processor.

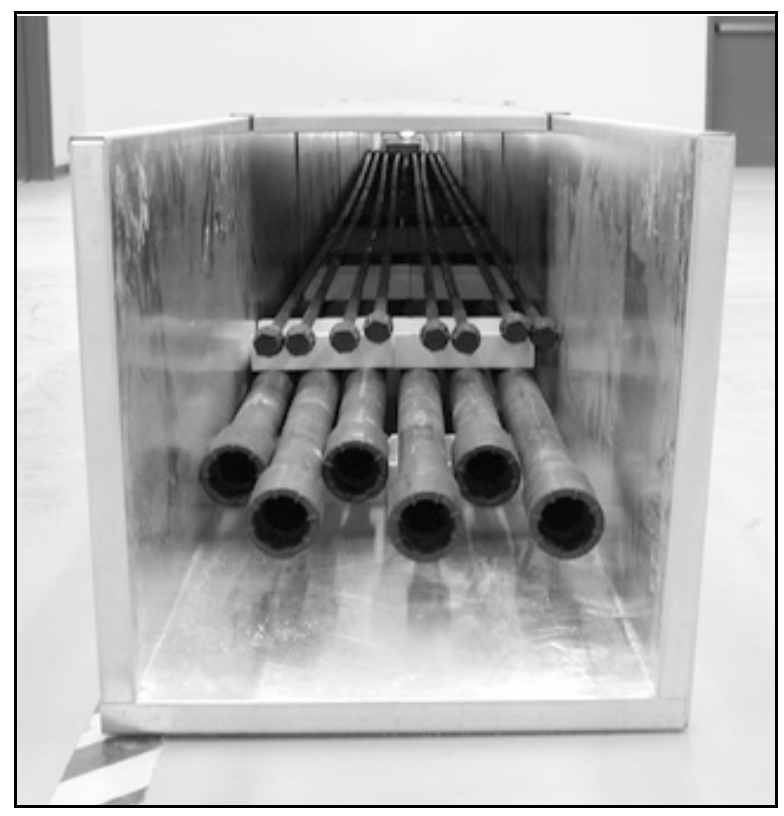

Figure 2. Rods and tubing in cryogenic processor.

Cryogenic processor walls consist of a one inch layer of perlite insulation with sheet metal covering. The entire cryogenic processor is wrapped in a four inch layer of foam insulation. Thermocouples within the cryogenic processor ensure even dispersal of liquid $\mathrm{N}_{2}$. Ceramic blocks provide support for the components within the cryogenic processor.

Well selection. Three wells were initially selected, based on histories of production component failures due to abnormal wear: 52-2-SX3, 62-16-SX3, and 73-3-SX3. These wells produce from the Shannon Formation at depths of about $500 \mathrm{ft}$. During testing, well 62-16-SX3 was accidentally pumped off and operated dry for a period time, resulting in 
abnormal wear rates. RMOTC recommended that test data from this well be reserved, and Cryocon concurred. Raw data for well 62-16-SX3 are included in the appendices.

Production data for the test wells are as follows:

\begin{tabular}{|c|c|c|c|}
\hline API & Well \# & Oil Cum BBLS & Water Cum BBLS \\
\hline 4902522510 & $73-3-$ SX3 & 11,741 & 223,240 \\
\hline 4902522514 & $52-2-S X 3$ & 8,468 & 105,173 \\
\hline
\end{tabular}

Nominal production at the start of the test period was:

- 52-2-SX3: 5 BOPD 36API, 78 BWPD

- 73-3-SX3: 1 BOPD 36 API, 23 BWPD

Test procedure. CRADA \# 2000-010 was executed on 9/18/00. The Joint Work Statement (JWS) specified that RMOTC provide rods, couplings, pumps, and tubing, and that Cryocon provide the treatment. Each well had four joints of tubing, five rods, and five couplings each for Phases 1 and 2, for a total (for three wells) of 12 joints of tubing, 15 rods, and 15 couplings. On 9/19/00, an order was placed with Wilson Supply for components with these specifications:

- Rods: API Grade D, AISI 4720 nickle-chromium-moly alloy steel, 0.75 X 25'.

- Couplings: API Chss T, 8630 alloy steel.

- Tubing: API Class J-55, 4.70 lb./ft, 2 3/8” OD, gage 0.190 wall, nominal 31 ft. length.

- Pumps (provided by Rex Bell of Harbison Fischer):

52-2-SX3: Serial HF-9, 108" untreated chrome barrel, 54" valve rod.

73-3-SX3: Serial HFTRT-1, 108" treated chrome barrel, 54" treated valve rod. 62-16-SX3: Serial HFTRT-2, 120” treated carburized barrel, 72” valve rod.

Welded tubing provides more uniform wall thickness manufacturing tolerances. Some problems were encountered in ordering the tubing. The initial shipment contained $27 / 8$ " tubing. The second shipment had the correct $23 / 8$ " tubing, but was one joint short. The $24^{\text {th }}$ joint was eventually shipped, but was destroyed in an accident during handling.

Bob Phegley and Larry Castleman of ICO in Casper provided pre-and post-test tubing inspections. Upon receipt, the tubing was taken to the Casper ICO yard, where it was inspected on 10/24/01. No defective tubing was found during pre-test inspections. ICO uses NDT 5700 four function Electro Magnetic Induction measurement equipment to obtain wall thickness dimensions within a tolerance of 0.001 ”.

Sucker rods and couplings were acquired locally from Weatherford through Wilson Supply. API Grade D rods were not ideal for this test given their hardness. But the more desirable softer Grade C rods (AISI 1536 carbon-manganese steel) are not widely used and were not available within the time requirements of the test.

Each test component was stamped with a "T" or "U" for treated and untreated. Components to be treated ("T") were shipped to Cryocon, while untreated components 
("U") were moved to the field for use in the baseline testing phase. Cryocon applied different treatment profiles to components in each of the three wells, Profile \#1 (52-2SX3), Profile \#2 (62-16-SX3), and Profile \#3 (73-3-SX3). Cryocon did not identify with a stamping the individual components treated with each profile.

Accurate alloy information is critical to the design of Cryocon's descent and ascent profiles. Mark Quinn of Wilson Supply in Casper ensured that all components were manufactured in the same mill runs with identical Material Test Reports (MTR). MTRs provide data on alloy composition (see Appendix 1).

Initially, the plan was to test untreated components in Phase 1, with wells operating 24/7 for a nominal 90 calendar day period. Phase 2 would use treated components for another nominal 90 day period. Phase 1 (baseline untreated components) field testing began on 10/25/00, when well 52-2-SX3 was put on production. Baseline testing on well 73-3-SX3 started 12/6/00. The late start for well 73-3-SX3 was due to delays in receiving the cryogenically treated rod pump and valve rod. The same rod pumps were used continuously throughout Phases 1 and 2. Both wells were operated at 12 RPM with a 54" stroke. The wells were shut-in for 3 days on 1/13/01 to accommodate 3D seismic acquisition.

Well 52-2-SX3 operated on a 24 hour clock until being pulled on 2/5/01. Very little wear was noted on the untreated couplings and rods, so the testing periods for wells 52-2-SX3 and 73-3-SX3 were extended to a nominal 120 calendar days. (Note: Actual test periods are \pm 120 calendar days due to other oil field activity, manpower availability, mechanical problems, and weather.)

Well 52-2-SX3 continued on a 24 clock until being pulled on 3/13/01 with 118 calendar days of operation. Phase 2 treated components were installed. Well 73-3-SX3 was put on a 50\% clock due to low fluid levels, and pulled on 4/9/01 after 118 calendar days of operation. Phase 2 treated components were installed. The baseline untreated rods and couplings were moved to the water treatment building and measured.

The three test wells are located in a depleted ex-steamflood area of high water cut. In early June, well 62-16-SX3 pumped off and operated dry, leading to it's disqualification from the test. Production Operations, added chase water to a nearby idle steam injection well. Production from well 62-16-SX3 quickly went to $100 \%$ water. There was no reported oil/water ratio change in the other two wells. The duty cycle for well 73-3-SX3 was increased from $50 \%$ to $65 \%$ on $6 / 8 / 01$.

Phase 2 well pulls were conducted on 7/27/01 for well 52-2-SX3 after 127 calendar days of operation, and 8/8/01 for well 73-3-SX3 after 118 days. The treated rods and couplings were moved to the water treatment building and measured. On 8/13/01, all tubing was moved to ICO for measurement. A delay resulted as ICO awaited the ir plant's changeover to $23 / 8$ " tubing capability. On 8/30/01, ICO inspected 24 joints of tubing. 
Wear data acquisition and normalization. Rod and coupling OD dimensions were measured with a digital caliper to a tolerance of 0.01 ".

Nominal dimensions are:

- Coupling nominal OD (Figure 3): 1.63"

- Rod shoulder nominal OD (Figure 4): 1.49"

- Rod shank OD: 0.75"
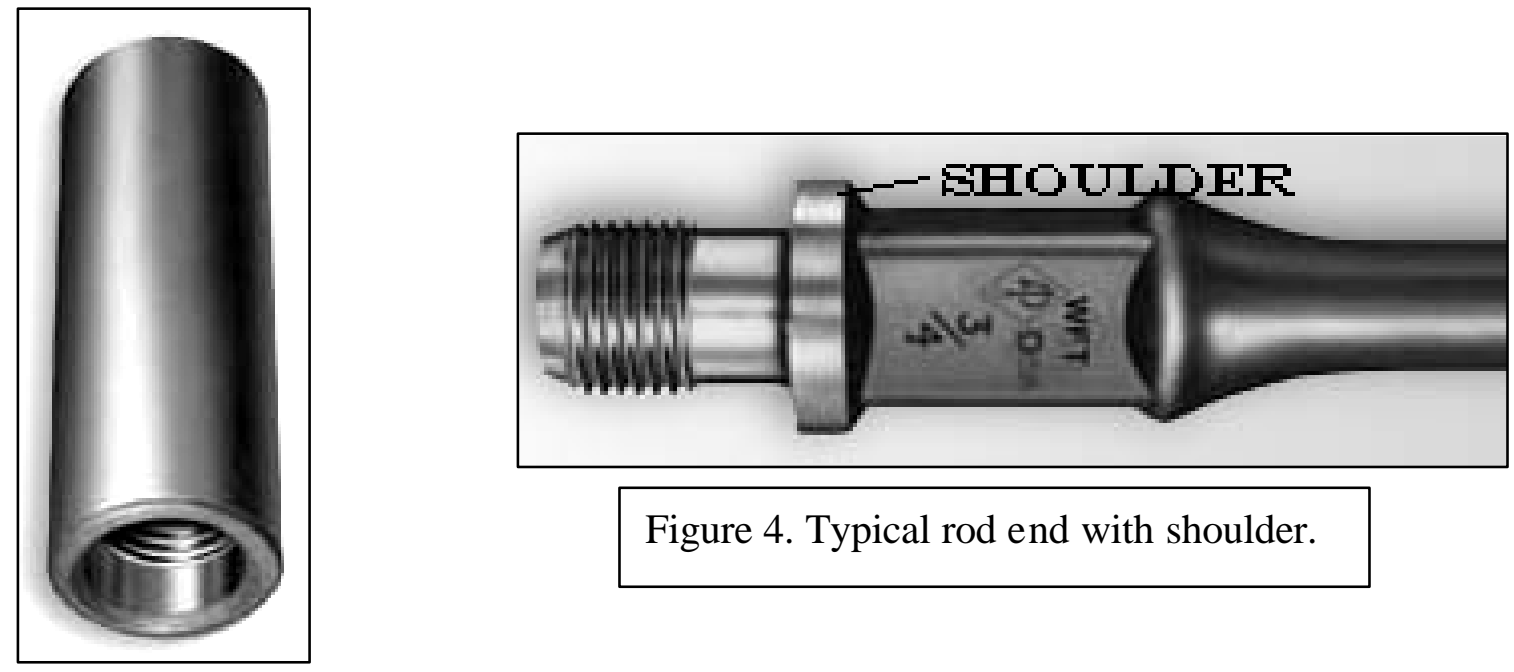

Figure 4. Typical rod end with shoulder.

Figure 3. Typical rod coupling.

Coupling wear was measured at the smallest OD. Rods were measured at the shoulder and mid-shank, where most wear occurs as the rod string spirals under compression. Excessive compression occurs when the rod string is improperly designed, or adjusted to tag the pump hard in order to break gas locks. Rod shoulders start wearing when the coupling OD has worn to the shoulder's OD.

Because of various operating constraints, the test wells did not operate for similar periods of time or duty cycles. Calendar days of operation were factored with duty cycles to arrive at total hours of operation in Table 1:

\begin{tabular}{|l|c|c|}
\hline \multicolumn{3}{|c|}{ TABLE 1. CRYOCON WELLS HOURS OF OPERATION } \\
\hline WELL & PHASE 1 & PHASE 2 \\
\hline $52-2-S X 3$ & 3048 & 3048 \\
\hline $73-3-S X 3$ & 1416 & 1632 \\
\hline
\end{tabular}

Measured wear was normalized in order for wear character between components in each well and test phase to be compared with operation time factored out. The theoretical wear rate in inches per hour was multiplied by 10,000 hours, yielding an extrapolated wear amount over 10,000 hours. This computation is for comparison purposes only, and is not a prediction of true wear amounts over 10,000 hours. 
Each component was assigned a number based on its position in the string, starting at the bottom. The rods were labeled 1-5, with \#1 being the lowest in the string and first to be run in the hole. Tubing used the same convention. Couplings were labeled 1PUMP, 1, 2, 3, 4, 5. Coupling \#1PUMP connected the lowermost rod (\#1) to the pump valve rod. Coupling \#1 was positioned at the top of rod \#1, and so on.

Coupling wear analysis. Cryocon's treatment showed improved durability. The raw coupling measurements for Phases 1 (baseline) and 2 (treated) are listed in Appendix 2. Tables 2 and 3 show the improvements in wear between Phases 1 and 2 in wells 52-2SX3 and 73-3-SX3 respectively. Wear data for well 73-3-SX3 are normalized to 10,000 hours because of the change in duty cycle during Phase 2 testing.

\begin{tabular}{|c|c|c|c|}
\hline \multicolumn{4}{|c|}{ TABLE 2. 52-2-SX3 COUPLING WEAR } \\
\hline COUPLING & PHASE 1 & PHASE 2 & $\%$ IMPROVEMENT \\
\hline 4 & 0.16 & 0.01 & $95 \%$ \\
\hline 3 & 0.06 & 0.01 & $89 \%$ \\
\hline 2 & 0.03 & 0.03 & $0 \%$ \\
\hline 1 & 0.27 & 0.07 & $75 \%$ \\
\hline 1PUMP & 0.11 & 0.08 & $25 \%$ \\
\hline AVERAGE IMPROVEMENT: & \multicolumn{3}{|c|}{} \\
\hline
\end{tabular}

\begin{tabular}{|c|c|c|c|}
\hline \multicolumn{4}{|c|}{ TABLE 3. 73-3-SX3 COUPLING WEAR } \\
\hline & PHASE 1 & PHASE 2 & \\
\hline & NORMALIZED & NORMALIZED & \\
\hline COUPLING & TO 10K HOURS & TO 10K HOURS & \% IMPROVEMENT \\
\hline 1PUMP & 0.12 & 0.03 & $74 \%$ \\
\hline 1 & 0.47 & 0.04 & $91 \%$ \\
\hline 2 & 0.41 & 0.02 & $94 \%$ \\
\hline 3 & 0.24 & 0.07 & $72 \%$ \\
\hline 4 & 0.37 & 0.39 & $-3 \%$ \\
\hline 5 & 0.90 & 0.47 & $48 \%$ \\
\hline AVERAGE IMPROVEMENT: & & $63 \%$ \\
\hline
\end{tabular}

Figure 5 summarizes wear improvement with cryogenically treated components. The poor responses for couplings \#2 in 52-2-SX3 and \#1 in 73-3-SX3 are unexplained at this time. 


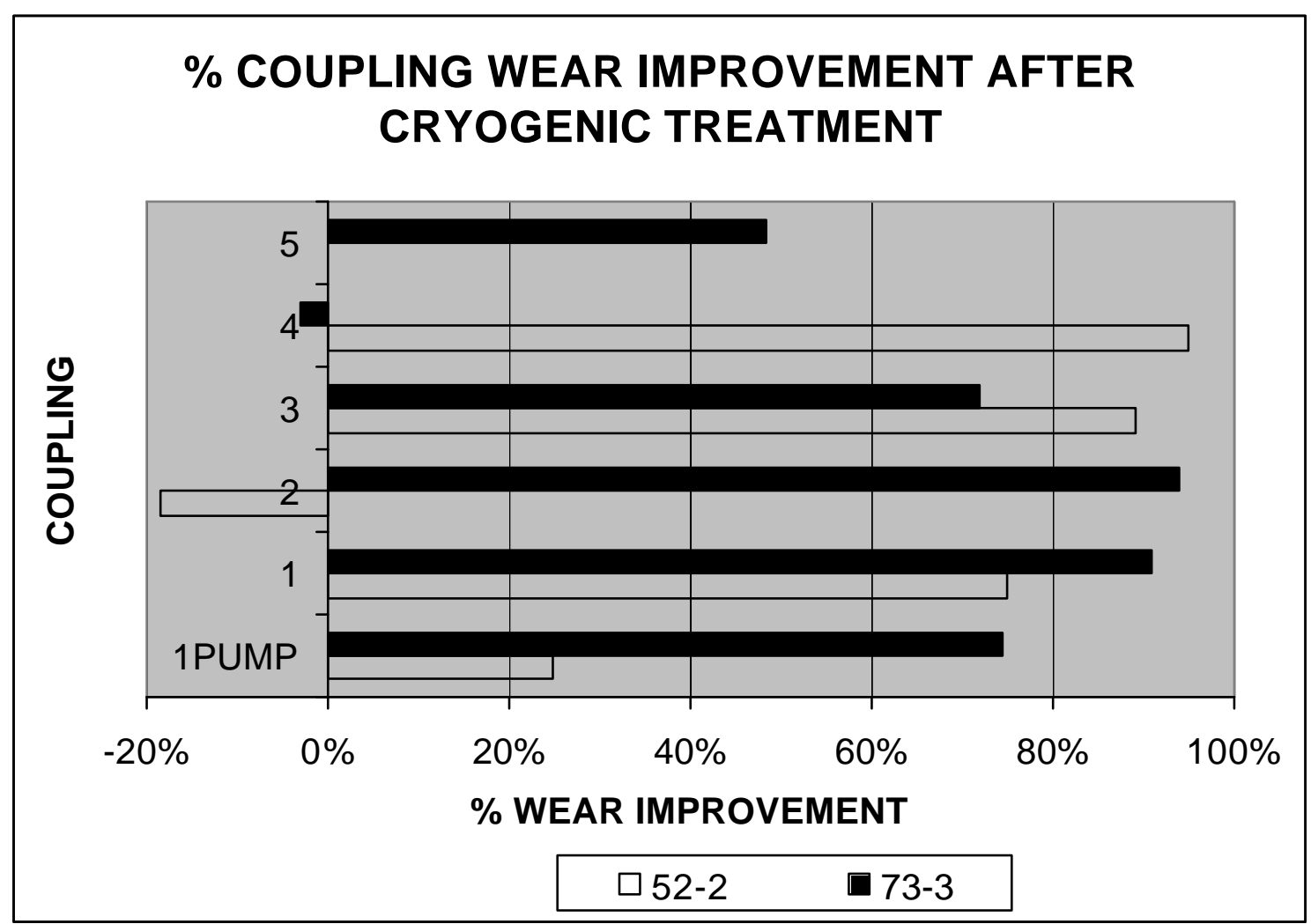

Figure 5. Coupling wear improvement in percent between Phase 1 and Phase 2.

Rod wear analysis. Phase 1 baseline rod wear was small in well 52-2-SX3, and essentially zero in well 73-3-SX3. Phase 2 cryogenically treated rods showed no wear in both wells, indicating improved wear character in well 52-2-SX3 (Tables 4). No table is included for well 73-3-SX3 since there was no wear in either test phase. The raw measurements are included in Appendix 3.

\begin{tabular}{|c|c|c|c|c|c|c|}
\hline \multicolumn{7}{|c|}{ TABLE 4. WELL 52-2-SX3 ROD WEAR } \\
\hline ROD & $\begin{array}{c}\text { UPPER SHOULDER } \\
\text { UN- } \\
\text { TREATED }\end{array}$ & TREATED & $\begin{array}{c}\text { MID SHANK } \\
\text { UN- } \\
\text { TREATED }\end{array}$ & TREATED & $\begin{array}{c}\text { LOWER SHOULDER } \\
\text { UN- } \\
\text { TREATED }\end{array}$ & TREATED \\
\hline 5 & 0.08 & 0.00 & 0.02 & 0.00 & 0.00 & 0.00 \\
\hline 4 & 0.02 & 0.00 & 0.01 & 0.00 & 0.02 & 0.00 \\
\hline 3 & 0.00 & 0.00 & 0.01 & 0.00 & 0.04 & 0.00 \\
\hline 2 & 0.00 & 0.00 & 0.00 & 0.00 & 0.00 & 0.00 \\
\hline 1 & 0.13 & 0.00 & 0.00 & 0.00 & 0.00 & 0.01 \\
\hline
\end{tabular}


Pump wear analysis. Well 52-2-SX3 operated with an untreated chrome barrel for a period of 6096 hours, and well 73-3-SX3 with a treated chrome barrel for 3048 hours. Raw measured data is included in Appendix 4. Because of the difference in operating time, barrel and valve rod wear data are normalized to 10,000 hours so a direct comparison of treated vs. untreated can be made (Table 5). As mentioned earlier, the treated carburized pump in well 62-16-SX3 had unusually high wear because of the well's operating condition.

Rex Bell of Harbison Fischer disassembled each pump and measured the barrel at six inch increments, and plungers and valve rods every three inches. Measurement accuracy was 0.0001 " on the barrel ID, and 0.001 " on the plunger and valve rod ODs. Nominal plunger-barrel clearance is $0.001 "$, and valve rod OD is 0.688 .

There was no difference in wear on the plungers between the two wells. The untreated chrome barrel (well 52-2-SX3) exhibited slightly more wear than the treated chrome barrel (well 73-3-SX3). Conversely, the treated valve rod (well 73-3-SX3) showed significantly more wear than the untreated rod (well 52-2-SX3). Chuck Tarr of Harbison Fischer had the pump components analyzed in the H-F metallurgy lab. They found the difference in wear character was due to corrosion, and that the cryogenic treatment had "little or no effect" on component wear resistance.

\begin{tabular}{|c|c|c|c|}
\hline \multicolumn{4}{|c|}{ TABLE 5. PUMP BARREL WEAR COMPARISON } \\
\hline \multicolumn{3}{|c|}{ NORMALIZED TO 10,000 HOURS } \\
\hline STA (IN.) & $\begin{array}{c}\text { UNTREATED } \\
\text { 52-2-SX3 } \\
\text { /10K HR }\end{array}$ & $\begin{array}{c}\text { TREATED } \\
\text { 73-3-SX3 } \\
\text { /10K HR }\end{array}$ & IMPROVEMENT \\
\hline 6 & 0.0000 & 0.0000 & 0.0000 \\
\hline 12 & 0.0008 & 0.0000 & 0.0008 \\
\hline 18 & 0.0008 & 0.0000 & 0.0008 \\
\hline 24 & 0.0003 & 0.0010 & -0.0007 \\
\hline 30 & 0.0003 & 0.0000 & 0.0003 \\
\hline 36 & 0.0003 & 0.0000 & 0.0003 \\
\hline 42 & 0.0003 & 0.0000 & 0.0003 \\
\hline 48 & 0.0003 & 0.0000 & 0.0003 \\
\hline 54 & 0.0003 & 0.0000 & 0.0003 \\
\hline 60 & 0.0003 & 0.0000 & 0.0003 \\
\hline 66 & 0.0003 & 0.0000 & 0.0003 \\
\hline 72 & 0.0008 & 0.0000 & 0.0008 \\
\hline 78 & 0.0008 & 0.0000 & 0.0008 \\
\hline 84 & 0.0008 & 0.0000 & 0.0008 \\
\hline 90 & 0.0008 & 0.0000 & 0.0008 \\
\hline 96 & 0.0008 & 0.0000 & 0.0008 \\
\hline 102 & 0.0033 & 0.0000 & 0.0033 \\
\hline 108 & 0.0008 & 0.0000 & 0.0008 \\
\hline
\end{tabular}


Pump valve rod wear analysis. Pump valve rods and guides have unusually high wear rates at NPR3, and so were added to the test at a late date. As with the pump barrels, valve rod wear is normalized to 10,000 hours so the two wells can be compared directly (Table 6). The results were a surprise, as the treated valve rod (well 73-3-SX3) exhibited generally more wear than the untreated rod (well 52-2-SX3). The possibility of the treated and untreated valve rods being accidentally switched has been ruled out. Due to a delay in receiving the treated valve rod, well 73-3-SX3 was the last to be put on test. No other valve rod was available to accidentally exchange.

\begin{tabular}{|c|c|c|c|}
\hline \multicolumn{4}{|c|}{ TABLE 6. PUMP VALVE ROD WEAR COMPARISON } \\
\hline \multicolumn{4}{|c|}{ NORMALIZED TO 10K HOURS } \\
\hline STA (IN.) & $\begin{array}{c}\text { UNTREATED } \\
\text { 52-2-SX3 } \\
\text { /10K HR }\end{array}$ & $\begin{array}{c}\text { TREATED } \\
\text { 73-3-SX3 } \\
\text { /10K HR }\end{array}$ & IMPROVEMENT \\
\hline 3 & 0.121 & 0.440 & -0.3182 \\
\hline 6 & 0.148 & 0.502 & -0.3543 \\
\hline 9 & 0.125 & 0.558 & -0.4331 \\
\hline 12 & 0.148 & 0.574 & -0.4265 \\
\hline 15 & 0.159 & 0.571 & -0.4117 \\
\hline 18 & 0.159 & 0.604 & -0.4446 \\
\hline 21 & 0.157 & 0.571 & -0.4134 \\
\hline 24 & 0.169 & 0.558 & -0.3888 \\
\hline 27 & 0.172 & 0.525 & -0.3527 \\
\hline 30 & 0.169 & 0.420 & -0.2510 \\
\hline 33 & 0.164 & 0.338 & -0.1739 \\
\hline 36 & 0.169 & 0.259 & -0.0902 \\
\hline 39 & 0.169 & 0.187 & -0.0180 \\
\hline 42 & 0.159 & 0.115 & 0.0443 \\
\hline 45 & 0.159 & 0.079 & 0.0804 \\
\hline 48 & 0.146 & 0.036 & 0.1099 \\
\hline 51 & 0.116 & 0.000 & 0.1165 \\
\hline 54 & 0.075 & 0.000 & 0.0755 \\
\hline
\end{tabular}

Tubing wear analysis. Larry Castleman of ICO reported that all tubing wall loss measured by their equipment was due to rod wear. Appendix 5 includes the raw wear data as recorded by ICO. Logs of internal wear locations were recorded and are included in Appendix 6. The treated and untreated tubing logs are presented adjacent to each other for a direct comparison of internal wear location. ICO rejects tubing with wall loss greater than $30 \%$. For a 0.190 " wall, the rejection threshold would be a wall thickness of 0.133 " or less.

Tables 7 and 8 depict treated and untreated tubing wear in each well normalized to 10,000 hours for easy comparison. Treated tubing in well 52-2-SX3 shows a distinct improvement in wear, especially joint \#4 where no wear was noted. The treated tubing in well 73-3-SX3 showed no advantage over untreated. 


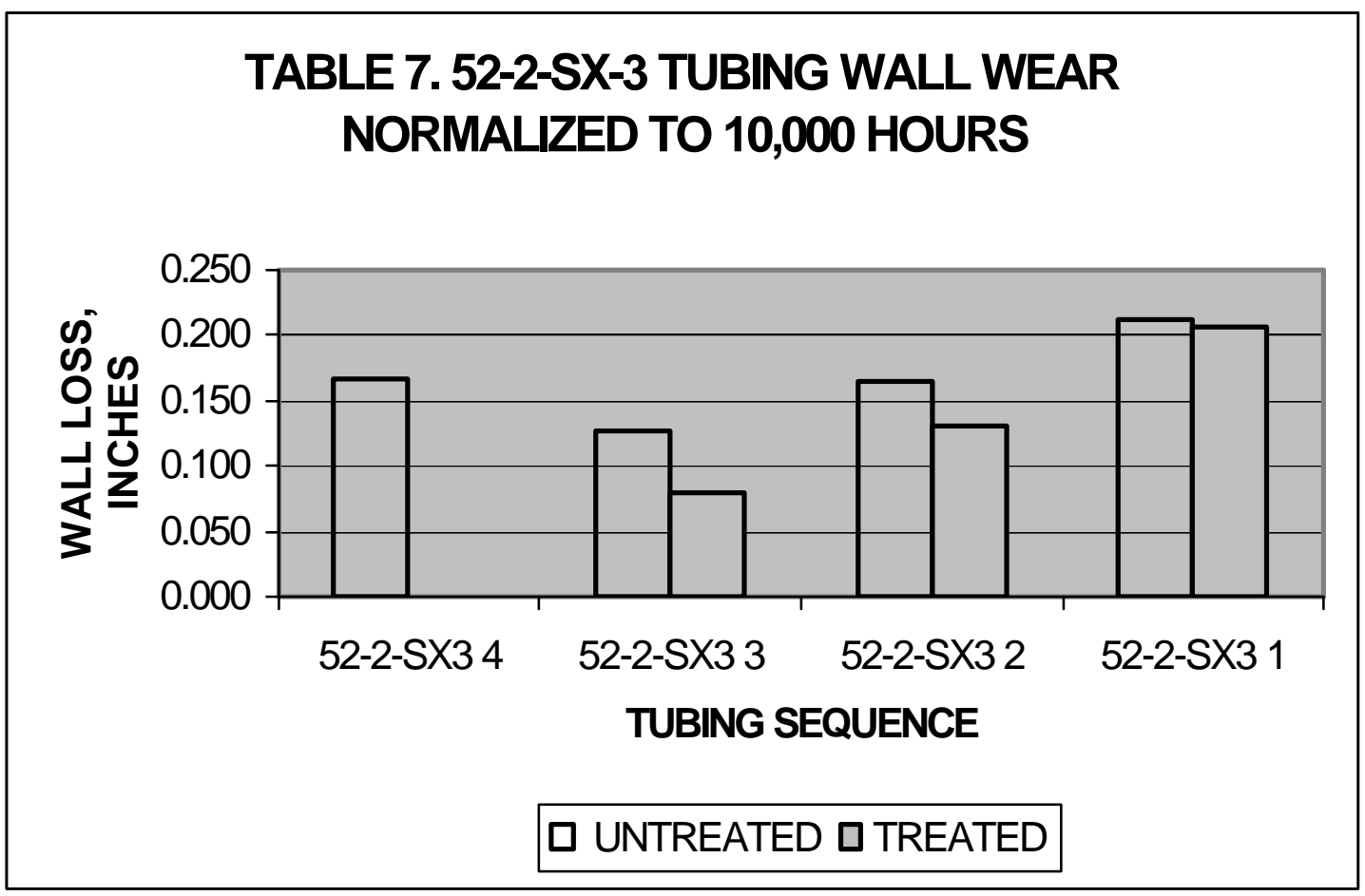

\section{TABE8733SX3TUBNGWALWEARNOFMALED TO10,000HOARS}

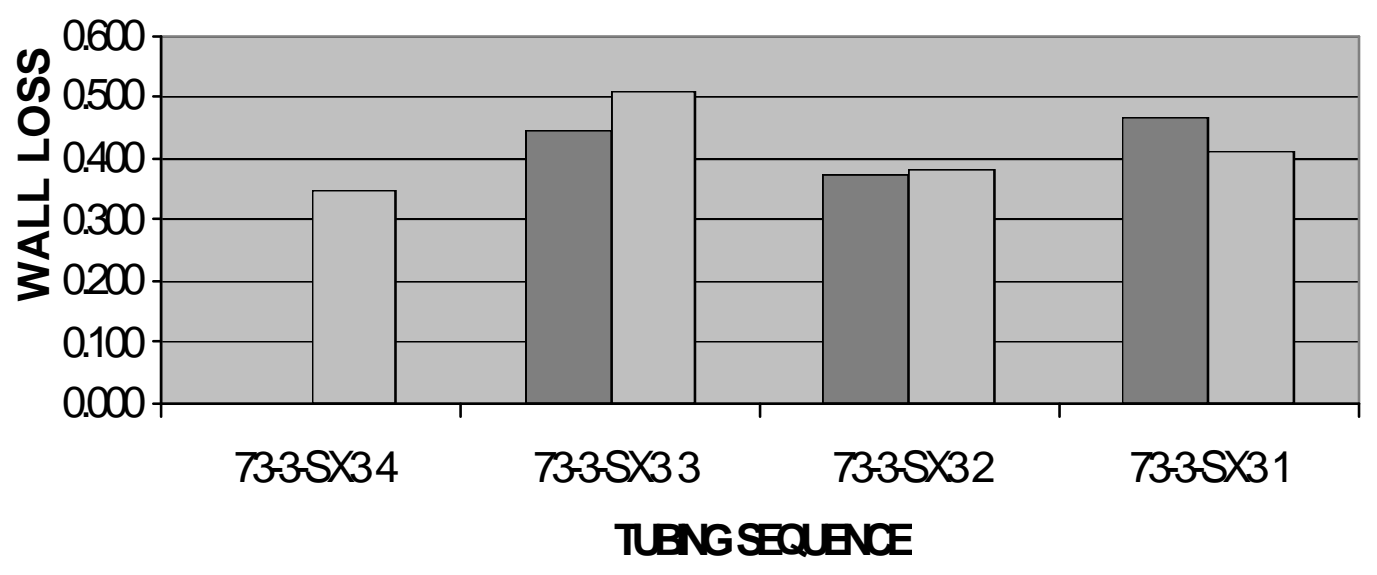

Q UNIREATED $\mathrm{TREATED}$ 



\section{PROJECT CONTACTS}

Doug Tunison, RMOTC Engineering Manager

U.S. Department of Energy

907 N. Poplar Suite 150

Casper, WY 82601

307 261-5161 Ext. 5006

Mark Milliken, RMOTC Project Coordinator

Critique, Inc.

907 N. Poplar Suite 150

Casper, WY 82601

307 261-5161 Ext. 5162

milliken@vcn.com

Miles Pierson, Cryocon Project Manager

$\mathrm{X}$ Tool, Inc. (a division of Cryocon)

2250 N. 1500 W.

Ogden, UT 84404

801 395-2796

milesp@cryocon.org

Bob Phegley and Larry Castleman

ICO Pipe and Sucker Rod Inspection and Reclamation

939 N. Robertson Rd.

Casper, WY 82604

$307472-9375$

Rex Bell

Harbison-Fischer

$6701 \mathrm{~W}$. Yellowstone Hwy.

Casper, WY 82604

$307472-7518$

Mark Quinn, Branch Manager

Wilson Supply

6577 W. Yellowstone Hwy.

Casper, WY 82604

$307472-5768$

casper@wilsononline.com 


\section{APPENDICES}

Appendix 1: Material Test Reports

Appendix 2: Coupling Wear Data

Appendix 3: Rod Wear Data

Appendix 4: Pump Wear Data

Appendix 5: Tubing Wear Data

Appendix 6: Tubing Wear Logs 
APPENDIX 1

Material Test Reports 
APPENDIX 2

Coupling Wear Data 


\begin{tabular}{|c|c|c|c|c|c|c|c|c|c|c|c|}
\hline \multicolumn{12}{|c|}{ CRYOCON TEST: COUPLING WEAR } \\
\hline \multicolumn{4}{|c|}{ MILLIKEN 8/01 } & \multicolumn{3}{|c|}{ UNTREATED } & \multicolumn{3}{|c|}{ TREATED } & \multirow[b]{2}{*}{ DIFF } & \multirow[b]{2}{*}{$\% \mathrm{IMP}$} \\
\hline WELL & $\begin{array}{c}\text { C. } \\
\text { DAYS }\end{array}$ & O. HRS & $\operatorname{COUP}^{*}$ & MIN DIA*A & WEAR & $" / 10 \mathrm{~K} \mathrm{HR}$ & MIN DIA ${ }^{*}$ & WEAR & "/10K HR & & \\
\hline $52-2-S \times 3$ & 127 & 3048 & 1PUMP & 1.52 & 0.11 & 0.36 & 1.55 & 0.08 & 0.27 & 0.09 & $25 \%$ \\
\hline $52-2-S X 3$ & 127 & 3048 & 1 & 1.36 & 0.27 & 0.88 & 1.56 & 0.07 & 0.22 & 0.66 & $75 \%$ \\
\hline $52-2-S \times 3$ & 127 & 3048 & 2 & 1.60 & 0.03 & 0.09 & 1.60 & 0.03 & 0.10 & -0.02 & $-19 \%$ \\
\hline $52-2-S X 3$ & 127 & 3048 & 3 & 1.57 & 0.06 & 0.21 & 1.62 & 0.01 & 0.02 & 0.19 & $89 \%$ \\
\hline $52-2-S \times 3$ & 127 & 3048 & 4 & 1.47 & 0.16 & 0.53 & 1.62 & 0.01 & 0.03 & 0.50 & $95 \%$ \\
\hline $62-16-S X 3$ & 118 & 2832 & 1PUMP & 1.62 & 0.01 & 0.03 & 1.46 & 0.17 & 0.60 & -0.16 & $-2025 \%$ \\
\hline $62-16-S X 3$ & 118 & 2832 & 1 & 1.61 & 0.02 & 0.07 & 1.49 & 0.14 & 0.49 & -0.12 & $-637 \%$ \\
\hline $62-16-S X 3$ & 118 & 2832 & 2 & 1.62 & 0.01 & 0.04 & 1.60 & 0.03 & 0.11 & -0.02 & $-167 \%$ \\
\hline $62-16-S X 3$ & 118 & 2832 & 3 & 1.62 & 0.01 & 0.05 & 1.57 & 0.06 & 0.20 & -0.04 & $-346 \%$ \\
\hline 62-16-SX3 & 118 & 2832 & 4 & 1.63 & 0.00 & 0.00 & 1.59 & 0.04 & 0.14 & -0.04 & $-3900 \%$ \\
\hline 73-3-SX3 & 118 & 1416 & 1PUMP & 1.61 & 0.02 & 0.12 & & & & & \\
\hline 73-3-SX3 & 118 & 1416 & 1 & 1.56 & 0.07 & 0.47 & & & & & \\
\hline 73-3-SX3 & 118 & 1416 & 2 & 1.57 & 0.06 & 0.41 & & & & & \\
\hline 73-3-SX3 & 118 & 1416 & 3 & 1.60 & 0.03 & 0.24 & & & & & \\
\hline 73-3-SX3 & 118 & 1416 & 4 & 1.58 & 0.05 & 0.37 & & & & & \\
\hline 73-3-SX3 & 118 & 1416 & 5 & 1.50 & 0.13 & 0.90 & & & & & \\
\hline 73-3-SX3 & 118 & 1632 & 1PUMP & & & & 1.63 & 0.00 & 0.03 & 0.01 & $74 \%$ \\
\hline 73-3-SX3 & 118 & 1632 & 1 & & & & 1.62 & 0.01 & 0.04 & 0.06 & $91 \%$ \\
\hline 73-3-SX3 & 118 & 1632 & 2 & & & & 1.63 & 0.00 & 0.02 & 0.05 & $94 \%$ \\
\hline 73-3-SX3 & 118 & 1632 & 3 & & & & 1.62 & 0.01 & 0.07 & 0.02 & $72 \%$ \\
\hline 73-3-SX3 & 118 & 1632 & 4 & & & & 1.57 & 0.06 & 0.39 & -0.01 & $-3 \%$ \\
\hline 73-3-SX3 & 118 & 1632 & 5 & & & & 1.55 & 0.08 & 0.47 & 0.05 & $48 \%$ \\
\hline
\end{tabular}


APPENDIX 3

Rod Wear Data 
ROD WEAR DATA

\begin{tabular}{|c|c|c|c|c|c|c|c|c|c|c|c|c|c|c|}
\hline \multirow[b]{2}{*}{ WELL } & \multirow[b]{2}{*}{ DAYS } & \multirow[b]{2}{*}{ ROD } & \multicolumn{2}{|c|}{ U/U SHOULDER } & \multicolumn{2}{|c|}{ T/U SHOULDER } & \multicolumn{2}{|c|}{ U/MID SHANK } & \multicolumn{2}{|c|}{ T/MID SHANK } & \multicolumn{2}{|c|}{ U/L SHOULDER } & \multicolumn{2}{|c|}{ T/L SHOULDER } \\
\hline & & & MIN DIA & WEAR & MIN DIA ${ }^{* \star}$ & WEAR & MIN DIA ${ }^{\star \star}$ & WEAR & MIN DIA $^{\star *}$ & WEAR & MIN DIA ${ }^{\star \star}$ & WEAR & MIN DIA ${ }^{\star \star}$ & WEAR \\
\hline $52-2-S X 3$ & 127 & 1 & 1.36 & 0.13 & 1.49 & 0.00 & 0.75 & 0.00 & 0.75 & 0.00 & 1.49 & 0.00 & 1.48 & 0.01 \\
\hline $52-2-S X 3$ & 127 & 2 & 1.49 & 0.00 & 1.49 & 0.00 & 0.75 & 0.00 & 0.75 & 0.00 & 1.49 & 0.00 & 1.49 & 0.00 \\
\hline $52-2-S X 3$ & 127 & 3 & 1.49 & 0.00 & 1.49 & 0.00 & 0.74 & 0.01 & 0.75 & 0.00 & 1.45 & 0.04 & 1.49 & 0.00 \\
\hline $52-2-S X 3$ & 127 & 4 & 1.47 & 0.02 & 1.49 & 0.00 & 0.74 & 0.01 & 0.75 & 0.00 & 1.47 & 0.02 & 1.49 & 0.00 \\
\hline $52-2-S X 3$ & 127 & 5 & 1.41 & 0.08 & 1.49 & 0.00 & 0.73 & 0.02 & 0.75 & 0.00 & 1.49 & 0.00 & 1.49 & 0.00 \\
\hline $\mid$\begin{tabular}{|c|}
$62-16-S X 3$ \\
\end{tabular} & 118 & 1 & 149 & 0.00 & 146 & 0.03 & 075 & 00 & 0604 & 015 & & (2000 & 144 & 005 \\
\hline & & & & & & & & & & & & & & \\
\hline & 110 & 2 & 1.49 & 0.00 & 1.49 & 0.00 & 0.15 & 0.00 & 0.15 & 0.00 & 1.49 & 0.00 & 1.46 & 0.03 \\
\hline 62-16-SX3 & 118 & 3 & 1.49 & 0.00 & 1.49 & 0.00 & 0.74 & 0.01 & 0.75 & 0.00 & 1.49 & 0.00 & 1.49 & 0.00 \\
\hline$|62-16-S X 3|$ & 118 & 4 & 1.49 & 0.00 & 1.48 & 0.01 & 0.75 & 0.00 & 0.75 & 0.00 & 1.49 & 0.00 & 1.49 & 0.00 \\
\hline 62-16-SX3 & 118 & 5 & 1.49 & 0.00 & 1.45 & 0.04 & 0.75 & 0.00 & 0.75 & 0.00 & 1.49 & 0.00 & 1.48 & 0.01 \\
\hline & & & & & & & & & & & & & & \\
\hline 73-3-SX3 & 118 & 1 & 1.49 & 0.00 & & & 0.75 & 0.00 & & & 1.49 & 0.00 & & \\
\hline 73-3-SX3 & 118 & 2 & 1.49 & 0.00 & & & 0.75 & 0.00 & & & 1.49 & 0.00 & & \\
\hline 73-3-SX3 & 118 & 3 & 1.49 & 0.00 & & & 0.75 & 0.00 & & & 1.49 & 0.00 & & \\
\hline 73-3-SX3 & 118 & 4 & 1.49 & 0.00 & & & 0.75 & 0.00 & & & 1.49 & 0.00 & & \\
\hline 73-3-SX3 & 118 & 5 & 1.48 & 0.01 & & & 0.75 & 0.00 & & & 1.49 & 0.00 & & \\
\hline & & & & & & & & & & & & & & \\
\hline $\begin{array}{l}\text { NOMINAL } \\
\text { DIA: }\end{array}$ & & & 1.49 & & & & 0.75 & & & & 1.49 & & & \\
\hline
\end{tabular}


APPENDIX 4

\section{Pump Wear Data}




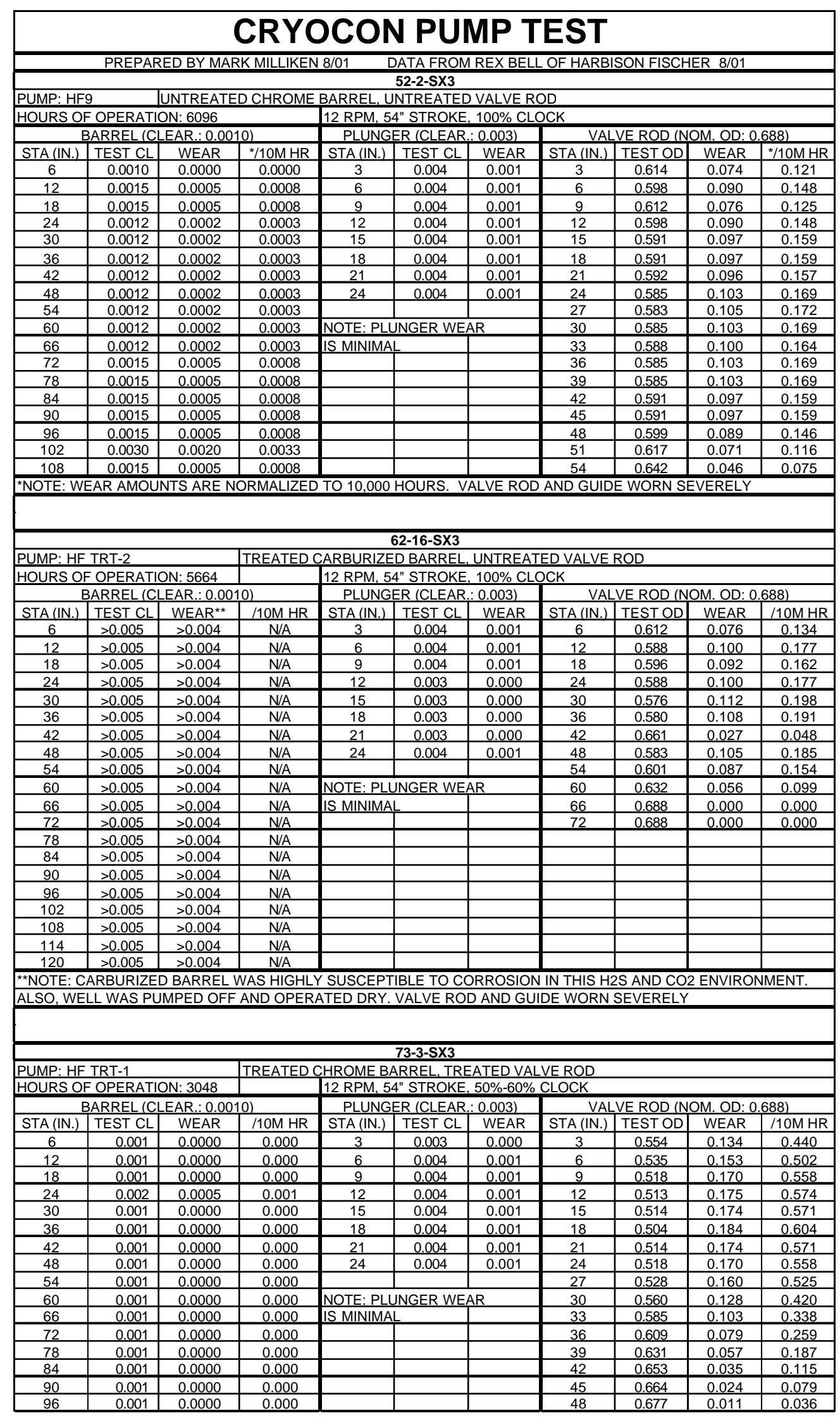


APPENDIX 5

\section{Tubing Wear Data}




\begin{tabular}{|c|c|c|c|c|c|}
\hline \multicolumn{6}{|c|}{ CRYOCON TUBING INSPECTION RESULTS } \\
\hline \multicolumn{6}{|l|}{ MILLIKEN 9/01 } \\
\hline STAMP & SEQ & WELL & WT & $\%$ LOSS & REJECT \\
\hline UA1 & 1 & $52-2-S \times 3$ & 0.125 & $34 \%$ & $\mathrm{x}$ \\
\hline TA1 & 1 & $52-2-S \times 3$ & 0.127 & $33 \%$ & $\mathrm{X}$ \\
\hline UA2 & 2 & $52-2-S \times 3$ & 0.140 & $26 \%$ & \\
\hline TA3 & 2 & $52-2-S \times 3$ & 0.150 & $21 \%$ & \\
\hline UA3 & 3 & $52-2-S \times 3$ & 0.151 & $21 \%$ & \\
\hline TB3 & 3 & $52-2-S \times 3$ & 0.166 & $13 \%$ & \\
\hline UA4 & 4 & $52-2-S \times 3$ & 0.139 & $27 \%$ & \\
\hline TB4 & 4 & $52-2-S \times 3$ & 0.190 & $0 \%$ & \\
\hline UB4 & 1 & $62-16-S \times 3$ & 0.159 & $16 \%$ & \\
\hline TA2 & 1 & $62-16-S \times 3$ & 0.123 & $35 \%$ & $\mathrm{X}$ \\
\hline UB3 & 2 & $62-16-S \times 3$ & 0.190 & $0 \%$ & \\
\hline TC4 & 2 & $62-16-S \times 3$ & 0.117 & $38 \%$ & $X$ \\
\hline UB2 & 3 & $62-16-S \times 3$ & 0.190 & $0 \%$ & \\
\hline TC2 & 3 & $62-16-S \times 3$ & 0.123 & $35 \%$ & X \\
\hline UB1 & 4 & $62-16-S \times 3$ & 0.190 & $0 \%$ & \\
\hline TA4 & 4 & $62-16-S \times 3$ & 0.141 & $26 \%$ & \\
\hline UC1 & 1 & $73-3-5 \times 3$ & 0.124 & $35 \%$ & $X$ \\
\hline TC1 & 1 & 73-3-SX3 & 0.123 & $35 \%$ & $X$ \\
\hline UC2 & 2 & 73-3-SX3 & 0.137 & $28 \%$ & \\
\hline TC3 & 2 & $73-3-S \times 3$ & 0.128 & $33 \%$ & $\mathrm{X}$ \\
\hline UC3 & 3 & 73-3-SX3 & 0.127 & $33 \%$ & $\mathrm{X}$ \\
\hline TB1 & 3 & $73-3-S \times 3$ & 0.107 & $44 \%$ & 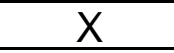 \\
\hline UC4 & 4 & $73-3-5 \times 3$ & 0.190 & $0 \%$ & $X$ \\
\hline TB2 & 4 & 73-3-SX3 & 0.133 & $30 \%$ & $\mathrm{X}$ \\
\hline
\end{tabular}




\section{APPENDIX 6}

\section{Tubing Wear Logs}



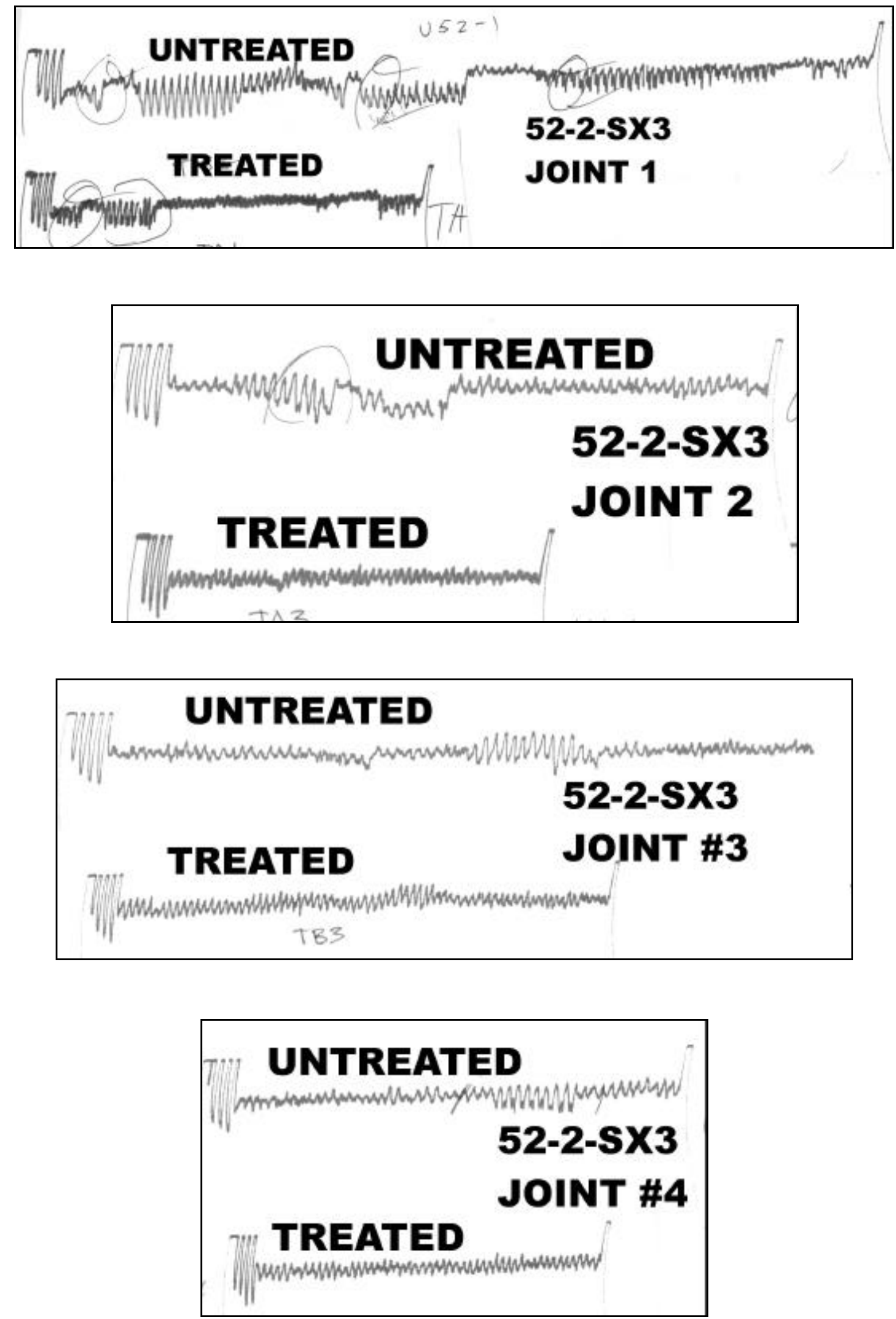


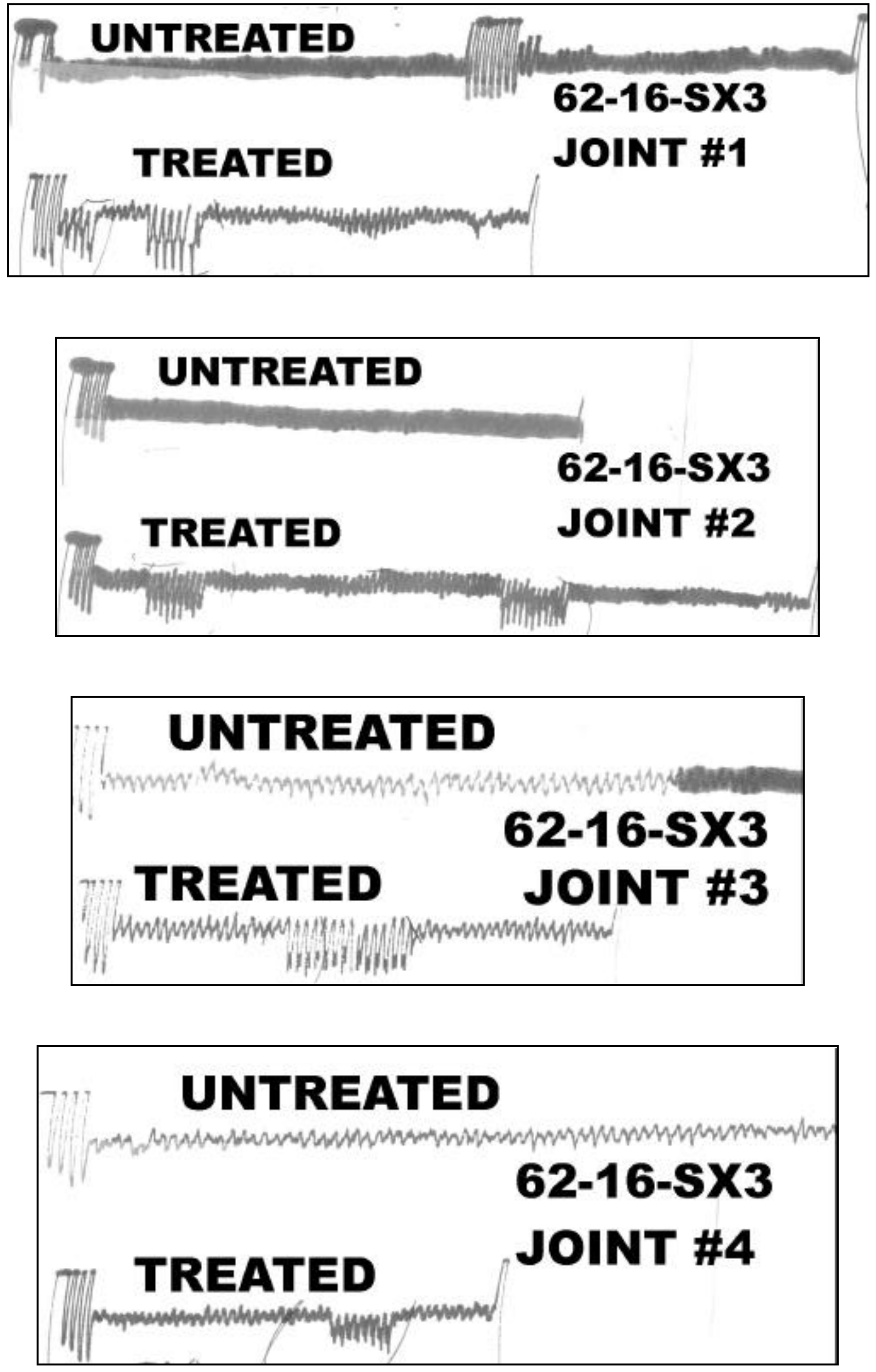


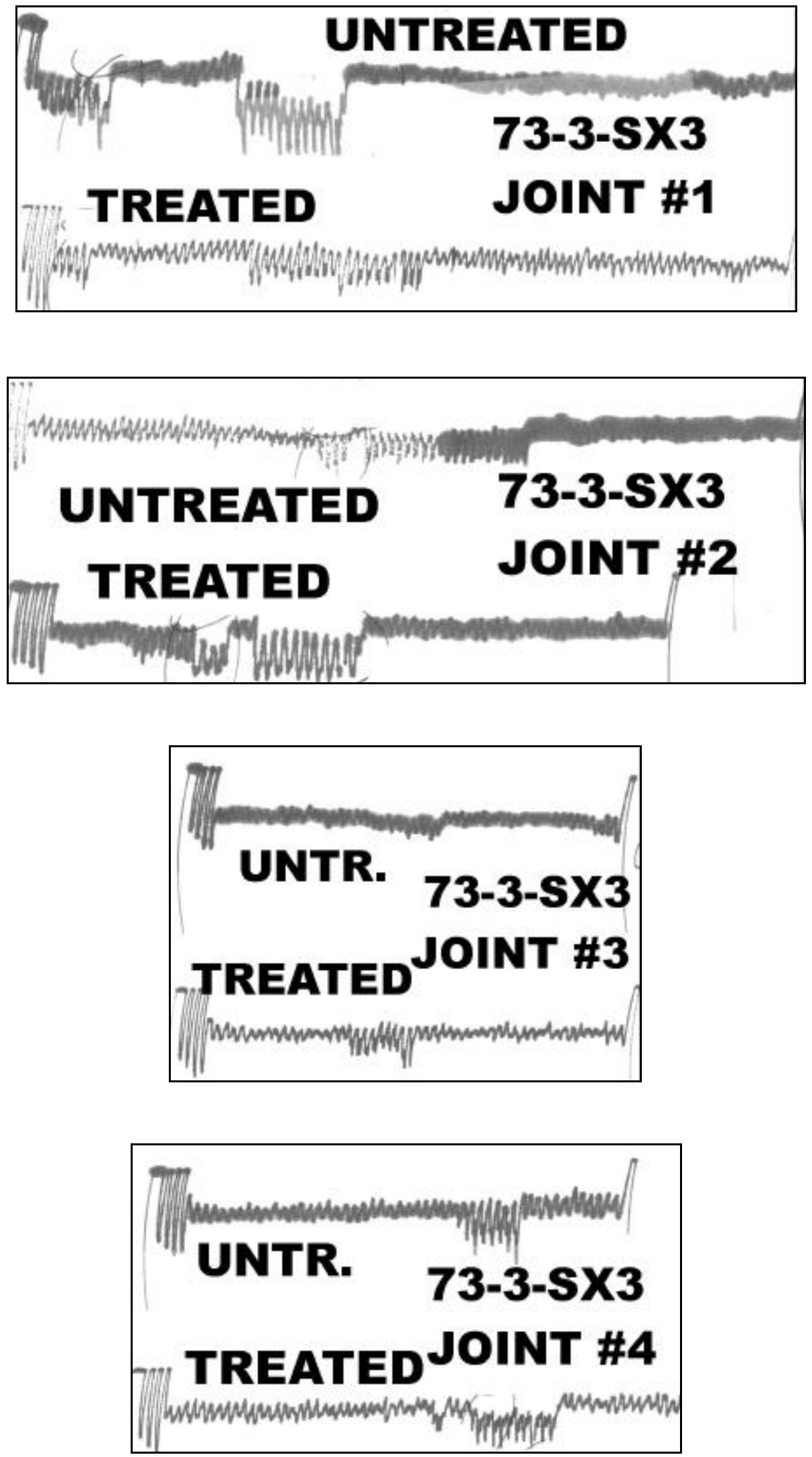